\section{THU0113 EXPRESSION OF GALECTIN-3 IN RHEUMATOID ARTHRITIS SYNOVIUM}

${ }^{1}$ S Kuchen, ${ }^{1}$ CA Seemayer, ${ }^{1} P$ Kuenzler, ${ }^{1}$ RE Gay, ${ }^{2}$ ME Billingham, ${ }^{1}$ BA Michel, ${ }^{1} S$ Gay, ${ }^{1} \mathrm{M}$ Neidhart. ${ }^{1}$ Center of Experimental Rheumatology, Department Rheumatology, University Hospital, Zürich, Switzerland; ' $V$ Veterinary School, University of Bristol, Bristol, UK

10.1136/annrheumdis-2001.990

Background Galectin-3 is a beta-galactoside-binding protein and belongs to the large family of lectins, which play important roles in a variety of physiological and pathophysiological processes via their recognition of glycoconjugates. Galectin-3 is involved in the regulation of cell growth and apoptosis, cell aggregation/ adhesion and differentiation and is associated with cell transformation and metastasis in several tumours. Since it activates inflammatory cells by promoting cell-cell and cell-matrix interactions and acts as a chemoattractant on monocytes and macrophages, galectin-3 is suggested to play a role in inflammatory diseases. So far, galectin-3 has been shown to be expressed by monocytes and macrophages but not by $\mathrm{T}$ - and B-lymphocytes. Objectives Here we investigated the expression of galectin-3 in rheumatoid arthritis (RA) and osteoarthritis (OA) synovial tissues. Furthermore, we examined the expression of galectin-3 in cultured RA synovial fibroblasts (RA-SF) and OA synovial fibroblasts (OA-SF).

Methods Paraffin-embedded synovial tissue samples from RA (n $=7)$ and OA $(n=3)$ patients were analysed for expression of galectin-3 by immunohistochemistry (IHC) and/or non-radioactive in situ hybridization (ISH) using monoclonal mouse antigalectin-3 antibodies (Affinity bioreagents, clone A3A12) and galectin-3 specific digoxigenin-labelled RNA antisense probes, respectively. Immunohistochemical staining of CD68 with monoclonal mouse anti-human macrophage CD68 antibodies (DAKO, clone PG-M1) was performed on parallel sections. Isotype specific mouse IgG and sense RNA probes were used as negative controls. Expression of galectin-3 in cultured RA-SF $(\mathrm{n}=10)$ and OA-SF $(n=1)$ from passage 2-7 was examined by RT-PCR. Results Galectin-3 was found to be expressed in all RA synovial tissue samples. Positive cells were detected throughout the lining and sublining layer with a predominant expression in the sublining. In contrast, CD68 was mainly expressed in the lining layer. Endothelial cells of small vessels in the sublining were mostly positive for galectin-3, whereas endothelial cells of larger vessels were negative. Clusters of galectin-3/CD68 positive cells were located around vessels. Interestingly, galectin-3 was rarely expressed at sites of bone invasion, in contrast to CD68. In OA synovial tissues, galectin-3 and CD68 were expressed by some cells in the lining layer. All cultured RA- and OA-SF were tested positive for galectin-3 mRNA by RT-PCR.

Conclusion We conclude from our data that the expression of galectin-3 in RA synovium is not restricted to monocytes and macrophages. Moreover, we suggest that galectin-3 contributes to the inflammation rather than to the destructive processes at sites of invasion.

S. Kuchen supported by the EMDO Stiftung.

C. A. Seemayer supported by DAAD and by the Theodor und Ida Herzog-Egli Stiftung.

\section{THU0114 A77 1726 DECREASES CD69 UPREGULATION INDUCED BY IL-15 ON HUMAN PERIPHERAL BLOOD LYMPHOCYTES}

${ }^{1}$ AM Ortiz, ${ }^{1}$ A Laffon, ${ }^{2} \mathrm{Fl}$ Romero, ${ }^{1}$ I Gonzalez-Alvaro. ${ }^{1}$ Rheumatology Service, Hospital de La Princesa; ${ }^{2}$ Medical Department, Aventis Pharma, S. A., Madrid, Spain

\subsection{6/annrheumdis-2001.991}

Background We have previously described that cyclosporin A inhibits CD69 expression induced by IL-15 on human peripheral blood lymphocytes (PBL). ${ }^{1}$ The expression of CD69 has a putative role in the intercellular contact-mediated TNF-alpha production by macrophages and could be a potential target in the treatment of Rheumatoid Arthritis. In addition, Janus Kinase 3 (JAK3) has been involved in the signal transmission of the IL-2 and IL-15 receptors. Furthermore, it has been described that A77 1726 (the active metabolite of leflunomide) may inhibit the effect of some tyrosine kinases, including the JAK3.

Objectives To analyse the effect of A77 1726 upon the CD69 expression induced by different cytokines on PBL.

Methods Purified PBL from healthy donors were incubated with IL-2 (50 IU/ml), IL-6 (5 ng/ml), IL-15 (5 ng/ml), TNF-alpha (20 $\mathrm{ng} / \mathrm{ml})$, or medium, separately and in the presence of cyclosporin A $(0.1$ ? $10 \mu \mathrm{g} / \mathrm{ml})$ and/or A77 $1726(0.1$ ? $100 \mu \mathrm{M})$. After $24 \mathrm{~h}$ of culture, cells were washed and CD69 expression assessed through indirect immunofluorescence and flow cytometry. Data are shown as mean \pm SD. Paired Student $t$ test was used for statistical analysis.

Results Cells incubated with IL-15 in the presence of A77 1726 showed a significant lower CD69 expression than those incubated with IL-15 alone in a dose dependent manner $(\mathrm{p}<0.05$ for all concentrations). The highest inhibitory effect, without evidence of toxicity, was observed at $100 \mu \mathrm{M}$ with a reduction in CD69 expression of $47.3 \pm 20.3 \%(\mathrm{n}=6)$. A similar effect was achieved with a specific JAK3 inhibitor, 4-(4?-Hydroxyphenyl) amino-6,7-dimethoxyquinazoline. A77 1726 also significantly inhibited the effect of IL-2 and IL-6, but not the CD69 up-regulation mediated by TNF-alpha. Treatment of PBL with a combination of CsA $(0.1 \mu \mathrm{g} / \mathrm{ml})$ and A77 $1726(0.1-1 \mu \mathrm{M})$ induced a similar inhibition of the CD69 expression achieved with each of the drugs at the maximal dose assayed $(10 \mu \mathrm{g} / \mathrm{ml}$ and $100 \mu \mathrm{M}$, respectively).

Conclusion The inhibition of IL-15 induced CD69 expression on PBL by A77 1726 might be also responsible for the therapeutic effect of leflunomide in RA. Furthermore, the combination of cyclosporin A and leflunomide might be an interesting approach to the treatment of this disease, as demonstrated in an antigen induced arthritis model in rats. ${ }^{2}$

\section{REFERENCES}

1 Ortiz AM, García-Vicuña R, Sancho D, Laffon A, Sánchez-Madrid F, GonzálezÁlvaro I. Cyclosporin A inhibits CD69 expression induced on synovial fluid and peripheral blood lymphocytes by IL-15. J Rheumatol. 2000;21:2329-38

2 Thoss K, Henzgen S, Petrow PK, Katenkamp D, Brauer R. Immunomodulation of rat antigen-induced arthritis by leflunomide alone and in combination with cyclosporin A. Inflamm Res. 1996:45:103-7 